\title{
Genetic diversity and molecular epidemiology of outbreaks of Klebsiella pneumoniae mastitis on two large Chinese dairy farms
}

\author{
Jia Cheng, ${ }^{1 *}$ Man Zhou, ${ }^{1 *}$ Diego B. Nobrega, ${ }^{2}$ Herman W. Barkema, ${ }^{3}$ Siyu Xu, ${ }^{1}$ Mengyue Li, ${ }^{1}$ John P. Kastelic, ${ }^{3}$ \\ Yuxiang Shi, ${ }^{1,4}$ Bo Han, ${ }^{1} \dagger$ and Jian Gao ${ }^{1} \dagger$ \\ ${ }^{1}$ Department of Clinical Veterinary Medicine, College of Veterinary Medicine, China Agricultural University, Beijing 100193, P.R. China \\ ${ }^{2}$ Department of Population Medicine, Ontario Veterinary College, University of Guelph, Guelph, Ontario, Canada, N1G 2W1 \\ ${ }^{3}$ Department of Production Animal Health, Faculty of Veterinary Medicine, University of Calgary, 3330 Hospital Drive NW, Calgary, AB, Canada, \\ T2N 4N1 \\ ${ }^{4}$ College of Life Sciences and Food Engineering, Hebei University of Engineering, Handan, Hebei 056038, P.R. China
}

\section{ABSTRACT}

Klebsiella pneumoniae is an opportunistic and environmental mastitis-causing pathogen, with potential for contagious transmission. Repetitive element sequencebased PCR was used to determine genetic diversity and explore potential transmission and reservoirs for mastitis caused by $K$. pneumoniae on 2 large Chinese dairy farms. A total of 1,354 samples was collected from the 2 dairy farms, including milk samples from cows with subclinical and clinical mastitis, bedding, feces, feed, teat skin, and milking liners. Environmental samples were collected from all barns and milking parlors and extramammary samples from randomly selected dairy cows on both farms. In total, 272 and $93 \mathrm{~K}$. pneumoniae isolates were obtained from Farms A and B, respectively (with $\sim 8 \mathrm{~K}$ and $2 \mathrm{~K}$ lactating cows, respectively). Isolation rates from clinical mastitis (CM), subclinical mastitis ( $\mathrm{SCM}$ ), and environmental or extramammary samples were 34, 23 and 37\%, respectively for Farm A and 42,3 , and $34 \%$ for Farm B. The K. pneumoniae isolated from $\mathrm{CM}$ milk and extramammary or environmental sources had high genetic diversity (index of diversity $>90 \%$ ) on the 2 farms and from SCM on Farm A. However, on Farm B, 9 SCM isolates were classified as 2 genotypes, resulting in a relatively low index of diversity (Simpson's index of diversity $=0.39 ; 95 \%$ $\mathrm{CI}=0.08-0.70)$. Genotypes of $K$. pneumoniae causing mastitis were commonly detected in feces, bedding, and milking liners (Farm A), or from teat skin, sawdust bedding, and feed (Farm B). Based on its high level

\footnotetext{
Received July 20, 2020.

Accepted September 4, 2020.

*These authors contributed equally to this work.

†Corresponding authors: gaojian2016@cau.edu.cn and hanbo@cau
} .edu.cn of genetic diversity, we inferred $K$. pneumoniae was an opportunistic and environmental pathogen causing outbreaks of CM on these 2 large Chinese dairy farms. Nevertheless, that only a few genotypes caused SCM implied some strains had increased udder adaptability and a contagious nature or a common extramammary source. Finally, control of intramammary infections caused by $K$. pneumoniae on large Chinese dairy farms must consider farm-level predictors, as the 2 outbreaks had distinct potential environmental sources of infection.

Key words: bovine mastitis, Klebsiella pneumoniae, genotype, environment, extramammary sites

\section{INTRODUCTION}

Bovine mastitis is one of the most prevalent and costly diseases affecting dairy cattle worldwide. Klebsiella spp. has been frequently reported as a bacterial cause of mastitis in Canada (Olde Riekerink et al., 2008), the United States (Oliveira et al., 2013), and China (Gao et al., 2017, 2019; Cheng et al., 2019), usually causing severe udder inflammation, pronounced milk losses, and increased risk of culling (Schukken et al., 2012).

Mastitis-causing pathogens are classified as either contagious or environmental (based on their reservoirs). Transmission of major contagious intramammary pathogens is typically controlled with a 5-point contagious mastitis control plan (Neave et al., 1969). To include control of environmental mastitis pathogens, the control was extended to the National Mastitis Council's 10-point mastitis control plan (Ruegg, 2017; Klaas and Zadoks, 2018). Klebsiella pneumoniae, frequently isolated from various environmental sources on dairy farms, including bedding, alleyways, and holding pens, is considered to cause predominantly environmental mastitis (Verbist et al., 2011; Zadoks et al., 2011a). 
Outbreaks of Klebsiella spp. mastitis were associated with contaminated sawdust and shavings (Zdanowicz et al., 2004; Adkins and Middleton, 2017). In addition, Klebsiella spp. was also detected on dairy farms using sand bedding, potentially due to fecal shedding of Klebsiella spp. by clinically healthy lactating cows (Muñoz et al., 2006).

Analysis of bacterial genetic diversity is essential to infer reservoirs and mechanisms of transmission. Predominance of a single strain causing mastitis on dairy farms implies contagious transmission or multiple exposure to a common source (Klaas and Zadoks, 2018), whereas multiple molecular types causing disease are indicative of opportunistic, environmental infections (Muñoz et al., 2007a). Although genetic diversity of $K$. pneumoniae from mastitis was very high (Paulin-Curlee et al., 2008), a predominant $K$. pneumoniae genotype causing mastitis was detected on 1 farm (Muñoz et al., 2007a), indicating potential for contagious transmission.

Several molecular typing tools have been used to analyze genetic diversity of $K$. pneumoniae strains within and between dairy farms (Muñoz et al., 2007a; PaulinCurlee et al., 2007, 2008). Repetitive element sequencebased PCR (rep-PCR) typing method is an accurate molecular typing tool, especially when applied to a large number of isolates (Paulin-Curlee et al., 2007).

Large, well-managed dairy farms $(\geq 500$ lactating cattle; Gao et al., 2017) are now common in China and expected to increase in number (Dairy Association of China, 2017). Identification of potential sources and reservoirs of $K$. pneumoniae on large dairy farms in China is key for preventive measures to decrease risk of IMI caused by K. pneumoniae. Most reports on characterization of clinical mastitis (CM) caused by K. pneumoniae were from Europe (Verbist et al., 2011) or North America (Muñoz et al., 2007a); it is unclear whether their findings are relevant for the Chinese dairy industry. In the present study, we describe the molecular epidemiology of bovine mastitis caused by $K$. pneumoniae on 2 large Chinese dairy farms. Klebsiella pneumoniae from mastitic milk and environmental or extramammary samples were genotyped using rep-PCR to determine genetic diversity and explore potential reservoirs and transmission.

\section{MATERIALS AND METHODS}

\section{Farms}

Two freestall dairy farms with $\mathrm{CM}$ outbreaks were located in provinces in northern and southern China, $\sim 700 \mathrm{~km}$ apart (Table 1). When the outbreaks occurred, Farm A had 8,230 lactating Holstein-Friesian cows, whereas Farm B had 1,970 lactating Holstein-Friesian cows. Lactating cows from the 2 farms were kept in the same barns throughout their entire lactation. Recycled manure solids (50-60\% DM) were used as bedding on Farm A, whereas Farm B used fresh sand (dry cows and cows $<30$ DIM) or sawdust (cows $>30$ DIM). All cows were fed TMR (alfalfa, oat hay, corn silage, and concentrates). Lactating cows were milked 3 times/d in rotary milking parlors, and milking units were routinely serviced. The milking routine on both farms consisted of forestripping (3-5 squirts of milk), premilking teat dipping, drying the teat with a dry washed towel, attachment of milking clusters, automatic cluster removal and postmilking teat dipping. Commercial iodine-based teat dips were used for pre- and postmilking disinfection ( 0.25 and $0.5 \%$ solutions, respectively).

\section{Clinical Mastitis Outbreaks}

An outbreak, defined as an unusual increase in incidence of CM, was noticed on Farm A in January 2019 and on Farm B in May 2019. On Farm A, 145 new CM cases were diagnosed from January 1 to 8 , 2019 (estimated incidence of 0.8 cases/cow per year),

Table 1. Characteristics of the 2 Chinese dairy farms with outbreaks of Klebsiella pneumoniae mastitis

\begin{tabular}{lll}
\hline Source & Farm A & Farm B \\
\hline Herd size (lactating cows) & 8,230 & 1,970 \\
Average bulk tank SCC (cells/mL) & 130,000 & 150,000 \\
Bedding material & Recycled manure solids (50-60\% DM) & Sand and sawdust ${ }^{1}$ \\
Frequency of cleaning stalls (times/d) & 3 & 3 \\
Frequency of replacing bedding (times/wk) & 1 & 1 \\
Alley scraping (passes/hr) & 1 & 1 \\
Milking parlor & Rotary (80 sites) & Parallel (double 32$)$ \\
Frequency of milking (times/d) & 3 & 3 \\
Teat disinfectants & $0.25 \%$ and $0.5 \%$ iodine solution for pre- & $0.25 \%$ and $0.5 \%$ iodine solution for pre- and \\
\hline
\end{tabular}

${ }^{1}$ Dry cows and cows with $<30$ DIM were bedded with fresh sand, whereas stalls of the other lactating cows were bedded with sawdust. 
whereas in the entire month of December 2018, 140 cows had CM (estimated incidence of 0.2 cases/cow per year). In January 2018 (same month of the previous year), 132 cows had CM (estimated incidence of 0.2 cases/cow per year). One Farm B, 47 new CM cases were recorded by the farm veterinarians from May 1 to 10, 2019 (estimated incidence of 0.9 cases/cow per year). In April 2019, 37 cows (estimated incidence of 0.2 cases/cow per year) had CM, whereas in May 2018, 46 cows (estimated incidence of 0.3 cases/cow per year) had CM. For the remaining months, incidence rates were comparable between years (data not presented). Both farms cultured CM samples from all cases in onfarm microbiological laboratories. Bacterial identification procedures followed the National Mastitis Council guidelines (Adkins and Middleton, 2017) for identification of major mastitis pathogens; these included isolation and purification of bacteria on basal media and selective media (e.g., sheep blood agar, MacConkey agar, mannitol salt agar), colony characteristics, Gram staining and microscopic observation, catalase and coagulase tests, and biochemical identification. All milk samples from CM cases (145 and 47 from Farms A and $\mathrm{B}$, respectively) were cultured as described above. After bacterial identification, $K$. pneumonia was detected in $77(53 \%)$ and $29(62 \%)$ samples from Farms A and B, respectively. Thus, K. pneumoniae was suspected to be involved in a high proportion of CM cases (53 and $62 \%$ on Farms A and B, respectively). Thereafter, the Mastitis Diagnostic Laboratory of China Agriculture University (MDL-CAU; Beijing, China) was contacted and researchers from MDL-CAU immediately visited farms for evaluation of potential outbreaks. At Farm A, in the $15 \mathrm{~d}$ after our farm visit, a total of $257 \mathrm{CM}$ cases from 257 cows (estimated incidence of 0.8 cases/cow per year) was identified by the milkers and confirmed by farm veterinarians, based on clinical signs including abnormal milk or swollen udder or both. At Farm B, a total of $98 \mathrm{CM}$ cases from 98 cows (estimated incidence of 1 case/cow per year) was identified in the first 18 $\mathrm{d}$ after our farm visit. The CM cases were recorded and categorized as mild (only abnormal milk), moderate (abnormal quarter but no general signs) or severe (signs of systemic illness) mastitis (Pinzón-Sánchez and Ruegg, 2011).

\section{Milk Sample Collection}

After the MDL-CAU visit, veterinarians collected milk samples from affected quarters of all cows with $\mathrm{CM}$, before treatment was initiated. In addition, prevalence of subclinical $K$. pneumoniae mastitis during the same period was determined to study the association between isolates causing the 2 types of mastitis [CM and subclinical mastitis (SCM)]. A commercial California Mastitis Test (CMT) kit (DeLaval, Tumba, Sweden) was used to identify quarters with SCM (Schalm and Noorlander, 1957). Briefly, milk samples were collected from all 4 quarters of lactating cattle by the milkers after the first 3 streams of milk were discarded. Approximately $2 \mathrm{~mL}$ of milk from each quarter and an equal amount of CMT solution was mixed in each cup of the CMT paddle. After $20 \mathrm{~s}$, visible reactions were observed and scored. Quarters with CMT score $\geq 1$ (weak positive) were considered SCM. Thereafter, quarter samples were collected aseptically for bacteriological culture. In total, 4,651 quarter samples from 1,229 cows at Farm A (3 or $4 \mathrm{~d}$ after our farm visit) and 3,728 quarter samples from 1,013 cows at Farm B (3-5 d after our farm visit) were collected for SCM, respectively. Of them, 300 (Farm A) and 261 (Farm B) nonrepetitive quarter milk samples were aseptically collected from quarters identified as SCM by researchers from MDL-CAU. Cows from each barn were simultaneously sampled for CMT test by 4 or 5 milkers, based on the sequence of cows entering into the milking parlor. As a result, cows tested were those that had entered the milking parlors first. No barn-level information was recorded.

\section{Extramammary and Environmental Sample Collection}

Environmental samples were collected at a 1-time visit to all barns ( $\mathrm{n}=17$ on Farm $\mathrm{A}$ and $\mathrm{n}=8$ on Farm B) and milking parlors (1 per farm), and extramammary samples from randomly selected dairy cows on both farms (Table 2). Briefly, samples from randomly selected stall beddings were collected from Farm A (2 or 3 bedding samples per barn, $\mathrm{n}=48$ samples) and from Farm B ( 7 or 8 bedding samples per barn, including 23 samples from sand and 35 samples from sawdust bedding). Bedding material was sampled from the back third of cubicles not contaminated by feces, as described (Muñoz et al., 2006). Feed samples ( $\mathrm{n}=54$ and $\mathrm{n}=8$ on Farms A and B) were collected from feeding alleys. Within a barn, samples were distant from each other ( $>20$ head locks apart). Three or 4 samples per barn were collected on Farm A and 1 sample per barn was collected on Farm B. Bedding and feed samples were stored in clean, ziplock bags of appropriate size, and within $1 \mathrm{~h}$ were diluted in $20 \mathrm{~mL}$ of sterile PBS (Solarbio, Beijing, China). Fecal samples were collected from the rectum of randomly selected cows $(n=50$ 
Table 2. Isolation of Klebsiella pneumoniae from the 2 dairy farms

\begin{tabular}{|c|c|c|c|c|}
\hline Source & \multicolumn{2}{|c|}{ Farm A } & \multicolumn{2}{|c|}{ Farm B } \\
\hline Clinical mastitis & 257 & $88(34)$ & 98 & $41(42)$ \\
\hline Extramammary samples & 143 & $69(48)$ & 55 & $24(44)$ \\
\hline Teat skin & 93 & $36(39)$ & 31 & $18(58)$ \\
\hline Feces & 50 & $33(66)^{\mathrm{a}}$ & 24 & $6(25)^{\mathrm{b}}$ \\
\hline Feed & 54 & $4(7)^{a}$ & 8 & $4(50)^{\mathrm{b}}$ \\
\hline Milking equipment & 66 & $6(9)^{\mathrm{a}}$ & 6 & $1(17)^{\mathrm{b}}$ \\
\hline Total & 868 & $272(31)^{\mathrm{a}}$ & 486 & $93(19)^{b}$ \\
\hline
\end{tabular}

${ }^{\mathrm{a}, \mathrm{b}}$ Within a row, proportions without a common letter indicated a difference $(P<0.05)$ between the 2 farms.

${ }^{1}$ California Mastitis Test score $\geq 1$.

${ }^{2}$ From 58 bedding samples, 35 were collected from sawdust bedding and 23 were collected from fresh sand bedding on Farm B.

${ }^{3}$ All positive samples were isolated from sawdust bedding; isolation rate of K. pneumoniae from sawdust bedding on Farm B was $40 \%$.

and $\mathrm{n}=24$ on Farms A and B, respectively) using a PBS-imbued sterile cotton swab; 2 or 3 cows per barn were sampled on Farm A, and 3 cows per barn were sampled on Farm B. Swabs were also used for collecting samples from teat skin $(\mathrm{n}=93$ and $\mathrm{n}=31$ on Farms $\mathrm{A}$ and $\mathrm{B}$, respectively) and milking equipment $(\mathrm{n}=66$ and $n=6$ on Farms A and B, respectively). Teat skin samples were collected before predipping, as described, with some modifications (Muñoz et al., 2008) using a PBS-imbued sterile cotton swab. Briefly, swabs were rubbed vigorously against the skin 4 or 5 times for all 4 teats per cow, moving from root to end of teat. Five or 6 cows per barn on Farm A and 3 or 4 cows per barn on Farm B were randomly selected for teat skin sampling. Milking equipment samples were collected during milking; inner surfaces of milking liners were scraped with a cotton swab after removal of randomly selected milking units. Cotton swabs with samples from feces, teat skin, and milking equipment were soaked in $5 \mathrm{~mL}$ of sterile PBS.

\section{Identification of K. Pneumoniae}

Milk samples were stored at $4^{\circ} \mathrm{C}$ for $<12 \mathrm{~h}$ before culturing. Bacteriological culture procedures were conducted as described (Gao et al., 2017). In brief, $10 \mu \mathrm{L}$ of milk from each sample was plated onto a blood agar and a MacConkey agar plate and incubated at $37^{\circ} \mathrm{C}$ for 24 to $48 \mathrm{~h}$. Samples were considered culture-positive if 1 or more colonies were observed $(\geq 100 \mathrm{cfu} / \mathrm{mL}$; Verbeke et al., 2014). Milk samples with $\geq 3$ species were considered contaminated, unless Staphylococcus aureus or Streptococcus agalactiae were isolated. Putative Klebsiella isolates were identified based on colony morphology (Muñoz et al., 2006), and classified as $K$. pneumoniae based on citrate, motility, and indole testing (Adkins and Middleton, 2017). Extramammary and environmental samples were stored at $4^{\circ} \mathrm{C}$ for $<6$ $\mathrm{h}$ before culturing. Samples were swabbed aseptically onto MacConkey inositol adonitol carbenicillin agar plates (Qingdao Hope Bio-Technology, Shangdong, China) containing $10 \mathrm{mg} / \mathrm{L}$ carboxypenicillin solution (Qingdao Hope Bio-Technology) and incubated at $37^{\circ} \mathrm{C}$ for 24 to $48 \mathrm{~h}$ (Bagley and Seidler, 1978), and putative Klebsiella isolates were identified as described above for milk samples. A sample was considered positive if only $K$. pneumoniae colonies were detected in culture. One discriminative colony was randomly selected from the agar plate, inoculated in tryptone soybean broth (Aoboxing, Beijing, China) and incubated for $24 \mathrm{~h}$ at $37^{\circ} \mathrm{C}$. Broth cultures with $25 \%$ of glycerin were stored on farms at $-20^{\circ} \mathrm{C}$ before arrival at the MDL-CAU laboratory. Upon arrival, 16S rDNA sequencing (Frank et al., 2008) was used for species confirmation.

\section{DNA Extraction}

Genomic DNA of $K$. pneumoniae isolates was extracted from overnight culture using a bacterial DNA extraction kit (Transgen, Beijing, China) according to manufacturer's instructions. Integrity of genomic DNA was tested by electrophoresis. Crude DNA samples were frozen at $-20^{\circ} \mathrm{C}$.

\section{Repetitive PCR and Analysis}

Molecular typing of $K$. pneumoniae isolates was performed using rep-PCR, as described (Paulin-Curlee et al., 2007). A reaction mixture was prepared containing $25 \mu \mathrm{L}$ of Taqmix (Transgen), $1 \mu \mathrm{L}$ of primer $(10 \mu M), 1$ 
$\mu \mathrm{L}$ of template DNA, and $23 \mu \mathrm{L}$ of distilled water. The PCR conditions were $5 \mathrm{~min}$ at $94^{\circ} \mathrm{C}$, followed by repeated cycles $(\mathrm{n}=36)$ of $94^{\circ} \mathrm{C}$ for $1 \mathrm{~min}, 36^{\circ} \mathrm{C}$ for $1 \mathrm{~min}, 2 \mathrm{~min}$ at $72^{\circ} \mathrm{C}$, and a final extension at $72^{\circ} \mathrm{C}$ for $9 \mathrm{~min}$. The PCR products were electrophoresed on $1.5 \%$ agarose gels and DNA bands visualized by ethidium bromide staining. Gel images were uploaded and analyzed using InfoQuest FP software (Bio-Rad Laboratories, Hercules, CA). Dendrograms were built using unweight pair group method with arithmetic averages method, with use of the Dice coefficient (Qu et al., 2019). Optimization and position tolerance were set at 1.0 and $1.5 \%$, respectively. Genetic cluster relationships were mapped and similarities of $\geq 90 \%$ by rep-PCR were assigned to the same genotype. This threshold was chosen as repPCR analysis of $K$. pneumoniae isolated from mastitis had, on average, $93.6 \%$ repeatability (Paulin-Curlee et al., 2007).

\section{Statistical Analyses}

All analyses were done in $\mathrm{R}$ version 3.6.1 ( $\mathrm{R}$ Core Team, 2019; R Foundation for Statistical Computing, Vienna, Austria). Statistical significance was considered as $P<0.05$. Fisher's exact test was used to compare distribution of isolates between $\mathrm{CM}$ and SCM samples and between farms for each source. Additionally, Simpson's index of diversity (SID) and its respective $95 \%$ confidence interval (CI) was estimated according to farm and sample type (Simpson, 1949; Grundmann et al., 2001). The formula is shown below, where $S$ represents strata (e.g., farm, sample type), $N$ is the strata-specific total number of genotyped isolates, $G$ is the total number of genotypes detected within a stratum, and $n_{i}$ is the number of isolates assigned to the $i$ th specific genotype.

$$
S I D_{S}=1-\frac{1}{N(N-1)} \sum_{i=1}^{G} n_{i}\left(n_{i}-1\right)
$$

This index indicates the probability of 2 randomly selected strains from a population belonging to 2 genotypes (measures within-sample diversity). Overlapping of $95 \%$ CI was used for comparison of SID.

\section{RESULTS}

\section{Herd Characteristics}

On Farms A and B, mean annual milk production was 10,100 and $11,250 \mathrm{~kg}$, respectively, mean parity was 2.7 and $2.9(33,27$, and $40 \%$ of cows on Farm A and 30,26 , and $44 \%$ of cows on Farm B were parity 1, 2 , and $\geq 3$, respectively), and average bulk tank SCC was 160,000 and 145,000 cells $/ \mathrm{mL}$ in the year before the outbreak and 130,000 and 150,000 cells/mL in the month before the outbreak.

\section{Isolation Rates of K. Pneumoniae}

On Farms A and B, K. pneumoniae was detected in $88(34 \%)$ and $41(42 \%) \mathrm{CM}$ samples and $68(23 \%)$ and 9 (3\%) SCM samples, respectively (Table 2 ). Of K. pneumoniae CM cases, $41(47 \%)$ and $47(53 \%)$ were mild and moderate on Farm A, whereas 24 (59\%), 7 (17\%), and $10(24 \%)$ were mild, moderate and severe on Farm B. Except for K. pneumoniae, NAS, Escherichia coli, and other Enterobacter spp. were commonly isolated (isolation rate $>10 \%$ ) from CM samples on Farm A, whereas NAS and Streptococcus uberis were frequently isolated (isolation rate $>10 \%$ ) from SCM samples (Table 3). On Farm B, NAS and Streptococcus dysgalactiae were commonly isolated from both CM and SCM samples.

Klebsiella pneumoniae was detected in $116(37 \%)$ and $43(34 \%)$ samples from extramammary and environmental sources, including all 5 sources of samples (bedding, feces, feed, teat skin, and milking equipment) of both farms (Table 2). On Farm A, K. pneumoniae was most commonly detected in bedding samples (77\%), followed by feces $(66 \%)$, and teat skin (39\%) samples, with lesser detection proportion in milking equipment $(9 \%)$ and feed $(7 \%)$ samples. On Farm B, detection rate was highest in teat skin samples $(58 \%)$, followed by in feed (50\%), feces $(25 \%)$, bedding $(24 \%)$, and milking equipment (17\%). Of note, all 14 positive bedding samples were sawdust samples, with a $40 \%$ isolation rate from sawdust samples on Farm B. Isolation rates between the 2 dairy farms were distinct for SCM, bedding, feces, feed, and milking equipment samples $(P<$ $0.05)$.

\section{Within-Farm Genetic Diversity of K. Pneumoniae from CM and SCM}

On Farm A, 88 isolates from CM were classified into 38 distinct genotypic patterns. Genotype A-CM-1, 7, $8,9,10,11,12,13,15,19,22,25,30$, and 35 , each containing $\geq 3$ isolates, were the most prevalent genotypes (Figure 1). Among others, 5 genotypes contained 2 isolates and 19 genotypes were composed of a single isolate, yielding a SID of 0.97 (Figure 1; 95\% CI = 0.95-0.98). For the $68 \mathrm{SCM}$ isolates from Farm A, 
genotypes A-SCM-4, 5, 6, 7, 9, 13, 25 and 26 ( $\geq 3$ isolates for each) were most commonly detected, with an estimated SID of 0.97 (Figure 2; 95\% CI = 0.96-0.98).

Of Farm B, 41 CM K. pneumoniae isolates were genotyped into 15 patterns, with an estimated SID $=0.83$ (Figure 3; 95\% CI $=0.75-0.92$ ). Four genotypes contained $\geq 3$ isolates and 11 genotypes contained a single isolate. In addition, the $9 \mathrm{SCM}$ isolates from Farm B were grouped into 2 genotypes, with 1 genotype containing 7 isolates and the other containing 2 isolates. Therein, the estimated SID was 0.39 (Figure 4; 95\% CI $=0.08-0.70$ ).

\section{Within-Farm Genetic Diversity of K. Pneumoniae from Extramammary and Environmental Samples}

Of Farm A, 116 environmental and extramammary isolates were classified as 67 distinct genotypes. Genotypes A-E-1, 9, 11, 12, 13, 17, 19, 22, 28, 31, 33, 36, 40, 50 , and 51 each contained $\geq 3$ isolates from same source of environmental and extramammary samples. This increased diversity resulted in a SID of 0.99 (Supplemental Figure S1, https://doi.org/10.3168/jds.2020-19325; $95 \%$ CI $=0.98-0.99)$. Interestingly, some genotypes contained isolates from $>1$ site (e.g., A-E-11, A-E-17). On Farm B, 43 isolates from environmental or extramammary samples were classified as 18 genotypes, whereas 4 genotypes contained $\geq 6$ isolates (Supplemental Figure S2, https://doi.org/10.3168/jds.2020-19325; $\mathrm{SID}=0.92,95 \% \mathrm{CI}=0.88-0.95)$. Similarly, individual genotypes contained isolates from $>1$ site (e.g., B-E-3, B-E-4).

\section{Association Between Cow Parity and Genotypes}

From a total of $88 \mathrm{CM}$ isolates from Farm A, 17 were from heifers and belonged to 13 distinct genotypes (Figure 1), with a SID $=0.94(95 \%$ CI $=0.86-1.00)$. Regarding isolates from older cows $(\mathrm{n}=71), 33$ distinct genotypes were present on Farm A, with an estimated $\mathrm{SID}=0.96(95 \% \mathrm{CI}=0.93-0.98)$. On Farm B, 2 of $41 \mathrm{~K}$. pneumoniae $\mathrm{CM}$ isolates were from heifers and belonged to distinct genotypes (Figure 3).

\section{Potential Extramammary Sites of K. Pneumoniae from CM Cows}

On Farm A, 25 (28\%) of $88 \mathrm{~K}$. pneumoniae CM isolates were from genotypes that were also isolated from environmental or extramammary samples (Supplemental Figure S3, https://doi.org/10.3168/jds.2020-19325). Of the CM isolates, 18 isolates belonged to the same 5 genotypes that were also isolated from bedding material, whereas $9 \mathrm{CM}$ isolates shared 4 genotypes that were also obtained from fecal samples (Table 4). As for SCM, 30 (44\%) from 68 isolates belonged to genotypes that were also detected in at least 1 environmental or extramammary sample (Supplemental Figure S3). For SCM isolates, 16 were from same genotypes detected in feces and 10 from genotypes that were also recovered from milking liners (Table 4).

On Farm B, 16 (39\%) CM K. pneumoniae were from genotypes also detected in environmental or extramammary samples (Supplemental Figure S4, https://doi.org/10.3168/jds.2020-19325). There were $13 \mathrm{CM}$ isolates from the same genotype as 4 feed isolates

Table 3. Isolation of other pathogens (number and $\%$ of cases) from clinical mastitis cases on 2 dairy farms ${ }^{1}$

\begin{tabular}{|c|c|c|c|c|c|c|c|c|}
\hline$\frac{\text { Pathogen }}{\text { Escherichia coli }}$ & \multicolumn{4}{|c|}{ Farm A } & \multicolumn{4}{|c|}{ Farm B } \\
\hline Streptococcus uberis & 19 & $7 \%$ & 37 & $12 \%$ & - & - & 8 & $3 \%$ \\
\hline Streptococcus agalactiae & 2 & $1 \%$ & 5 & $2 \%$ & - & - & - & - \\
\hline Staphylococcus aureus & - & - & - & - & - & - & 2 & $1 \%$ \\
\hline Streptococcus dysgalactiae & 11 & $4 \%$ & 20 & $7 \%$ & 12 & $12 \%$ & 49 & $19 \%$ \\
\hline NAS + Escherichia coli & 2 & $1 \%$ & - & - & - & - & - & - \\
\hline Streptococcus uberis + E. coli & 1 & $0 \%$ & - & - & - & - & - & - \\
\hline S. uberis + NAS & - & - & 9 & $3 \%$ & - & - & - & - \\
\hline $\mathrm{NAS}+S$. dysgalactiae & - & - & - & - & - & - & 14 & $5 \%$ \\
\hline S. dysgalactiae + E. coli & - & - & - & - & 1 & $1 \%$ & - & - \\
\hline Contaminated $^{2}$ & 8 & $3 \%$ & 36 & $12 \%$ & 2 & $2 \%$ & 41 & $16 \%$ \\
\hline No growth & 43 & $17 \%$ & 47 & $16 \%$ & 16 & $16 \%$ & 50 & $19 \%$ \\
\hline
\end{tabular}

${ }^{1} \mathrm{CM}=$ clinical mastitis; $\mathrm{SCM}=$ subclinical mastitis.

${ }^{2}>2$ discriminative colonies observed on the blood agar plate. 


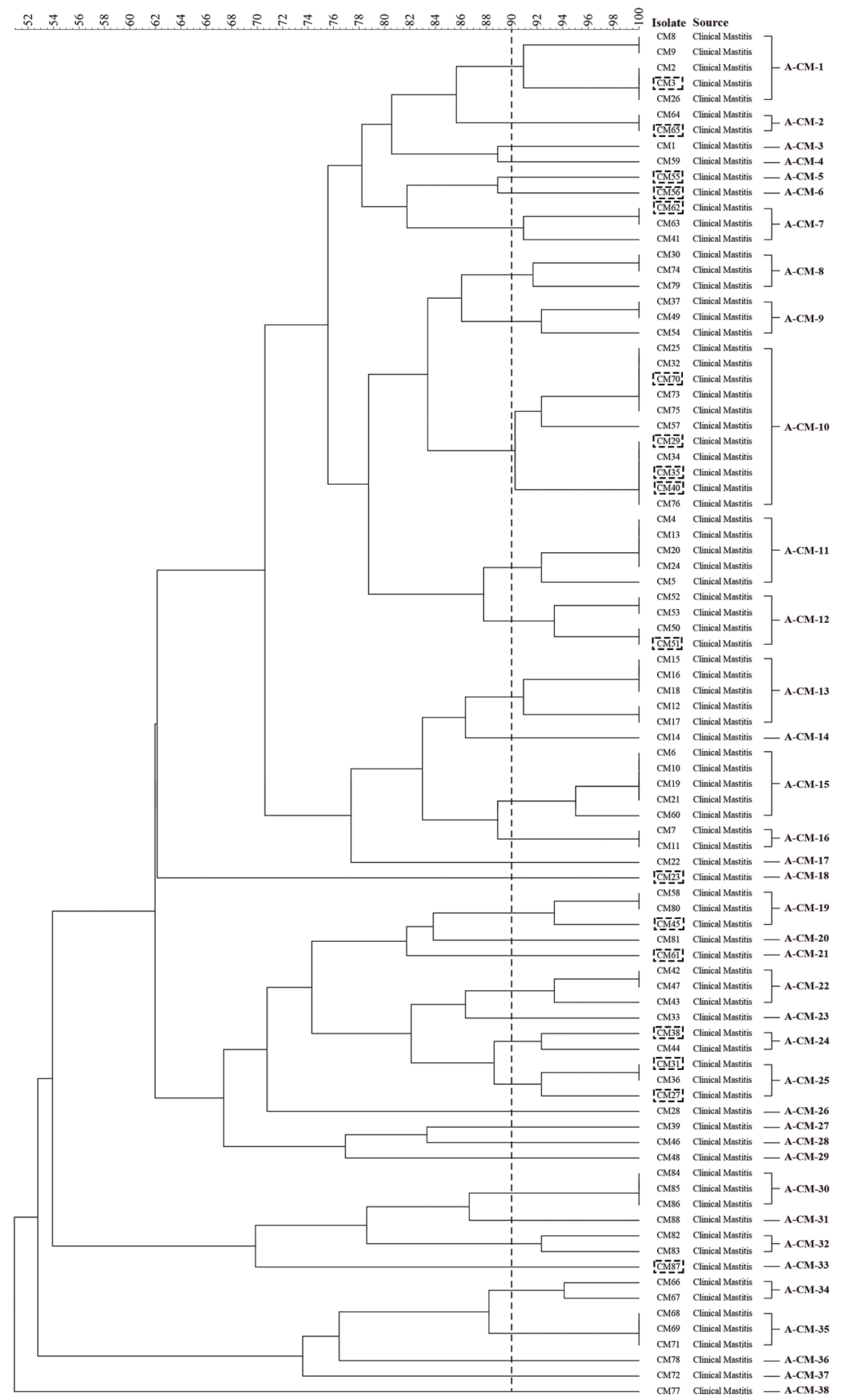

Figure 1. Repetitive DNA sequence PCR (rep-PCR) clustering of 88 Klebsiella pneumoniae isolates from CM on Farm A. Strains with similarity $\geq 90 \%$ were considered as same genotype. Klebsiella pneumoniae isolates $(\mathrm{n}=17)$ marked with boxes were isolated from heifers. 


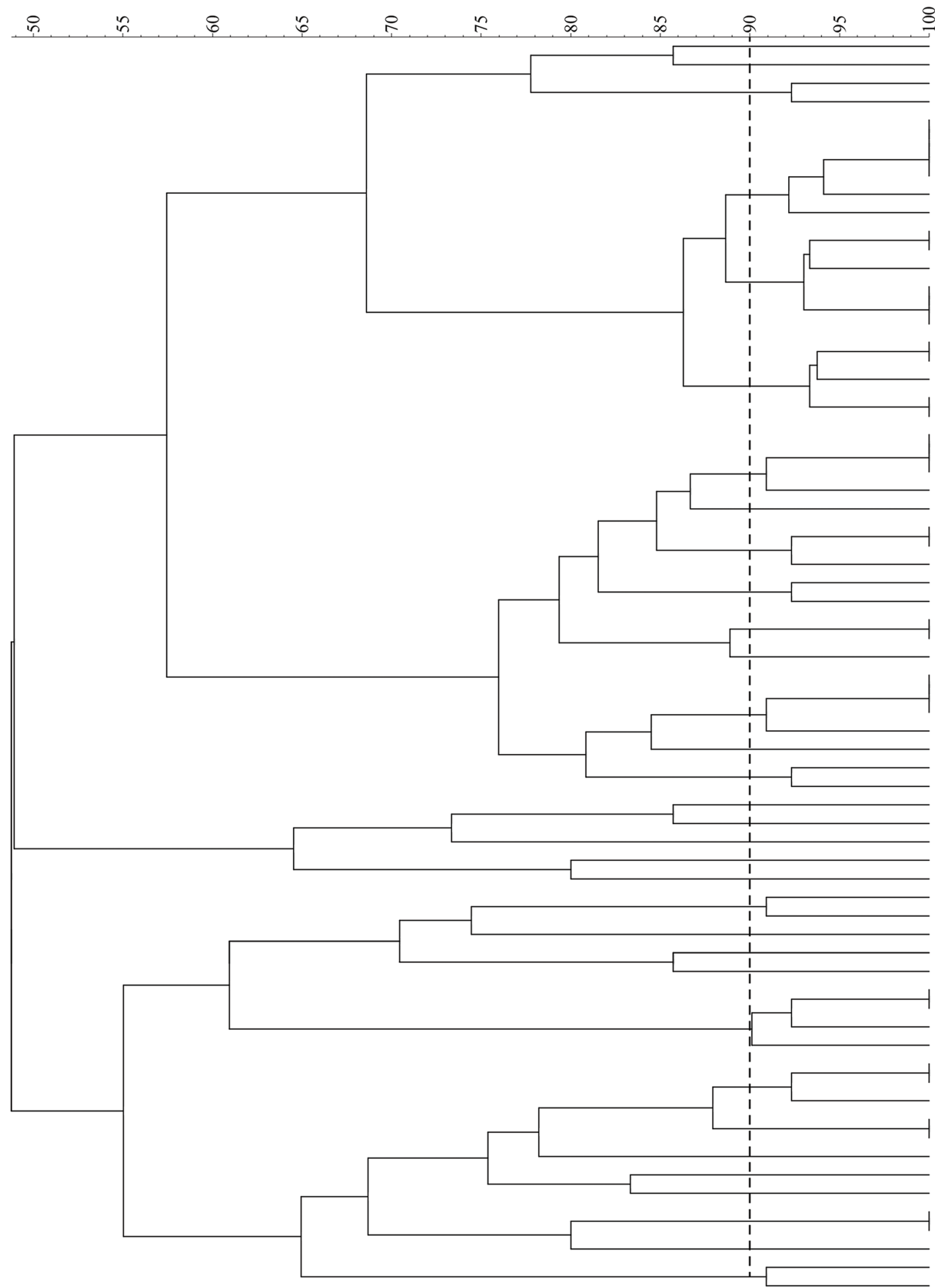

Isolate Source

SM24 Subclinical Mastitis - A-SCM-1

SM51 Subclinical Mastitis - A-SCM-2

SM14 Subclinical Mastitis - A-SCM-3

SM52 Subclinical Mastitis $-\mathbf{A}-\mathrm{SCM}$

SM60 Subclinical Mastitis

SM62 Subclinical Mastitis

SM64 Subclinical Mastitis

SM67 Subclinical Mastitis - A-SCM-4

SM56 Subclinical Mastitis

SM6 Subclinical Mastitis -

SM49 Subclinical Mastitis

SM68 Subclinical Mastitis

SM66 Subclinical Mastitis

SM5 Sublinimatis - A-SCM-5

SMIO Subclinical Mastitis

SM61 Subclinical Mastitis -

SM2 Subclinical Mastitis

SM57 Subclinical Mastitis

SM58 Subclinical Mastitis - A-SCM-6

SM55 Subclinical Mastitis

SM63 Subclinical Mastitis

SM3 Subclinical Mastitis

SM17 Subclinical Mastitis

SM18 Subclinical Mastitis - A-SCM-7

SM1 Subclinical Mastitis

SM54 Subclinical Mastitis - A-SCM-8

SM8 Subclinical Mastitis -

SM15 Subclinical Mastitis - A-SCM-9

SM53 Subclinical Mastitis -

SM7 Subclinical Mastitis

SM23 Subclinical Mastitis - A-SCM-10

SM21 Subclinical Mastitis

SM50 Subclinical Mastitis - A-SCM-11

SM22 Subclinical Masstitis - A-SCM-12

SM19 Subclinical Mastitis -

SM59 Subclinical Mastitis

SM65 Subclimical Mastitis - A-SCM-13

SM16 Subclinical Mastitis -

SM13 Subclinical Mastitis - A-SCM-14

SM4 Subclinical Mastitis ? A-SCM-15

SM9 Subclinical Mastitis

$\begin{array}{ll}\text { SM12 } & \text { Subclinical Mastitis - A-SCM-16 } \\ \text { SM26 } & \text { Subclinical Mastitis } \\ \text { - A-SCM-17 }\end{array}$

SM25 Subclinical Mastitis - A-SCM-18

SM20 Subclinical Mastitis - A-SCM-19

SM36 Subclinical Mastitis - A-SCM-20

SM11 Subclinical Mastitis 7- A-SCM-21

SM34 Subclinical Mastitis - A-SCM-22

SM31 $\quad$ Subclinical Mastitis - A-SCM-22

SM33 Subclinical Mastitis - A-SCM-24

SM37 Subclinical Mastitis

SM39 Subclinical Mastitis - A-SCM-25

SM40 Subclinical Mastitis

SM46 Subclinical Mastitis -

SM47 Subclinical Mastitis

SM48 Subclinical Mastitis - A-SCM-26

SM43 Subclinical Mastitis

SM27 Subclinical Mastitis

SM44 Subclinical Mastitis - A-SCM-2

SM35 Subclinical Mastitis - A-SCM-28

SM38 Subclinical Mastitis - A-SCM-29

SM42 Subclinical Mastitis - A-SCM-30

SM28 Subclinical Masstitis - A-SCM-31

SM32 Subclinical Mastitis - A-SCM-31

SM29 Subclinical Mastitis - A-SCM-32

SM41 Subclinical Mastitis -

SM45 Subclinical Mastitis - A-SCM-33

Figure 2. Repetitive DNA sequence PCR (rep-PCR) clustering of 68 Klebsiella pneumoniae isolates from SCM on Farm A. Strains with similarity $\geq 90 \%$ were considered the same genotype. 
and 2 teat skin isolates, whereas another 3 were also from genotypes detected in bedding samples (Table 5). Finally, all 9 SCM isolates from Farm B were classified as the same genotypes as isolates from bedding (Table 5; Supplemental Figure S4).

Sixty-seven genotypes were detected in environmental sources from Farm A, representing 54\% of Farm A genotypes, whereas for Farm B, 60\% of genotypes were detected in the environment, with no association between proportion of environmental genotypes and farm $(P=0.68)$. Similarly, 31 and $50 \%$ of genotypes were in CM for Farms A and B, respectively, with a tendency
$(P=0.06)$ for a difference between farms in proportion of genotypes in CM.

\section{DISCUSSION}

Increased incidence of CM with $K$. pneumoniae isolated from a high percentage of cases and high prevalence of $K$. pneumoniae in quarter milk samples implicated to be the causative pathogen of the 2 outbreaks of CM. Furthermore, 2 large dairy farms of distinct sizes, geographical locations and bedding types, en-

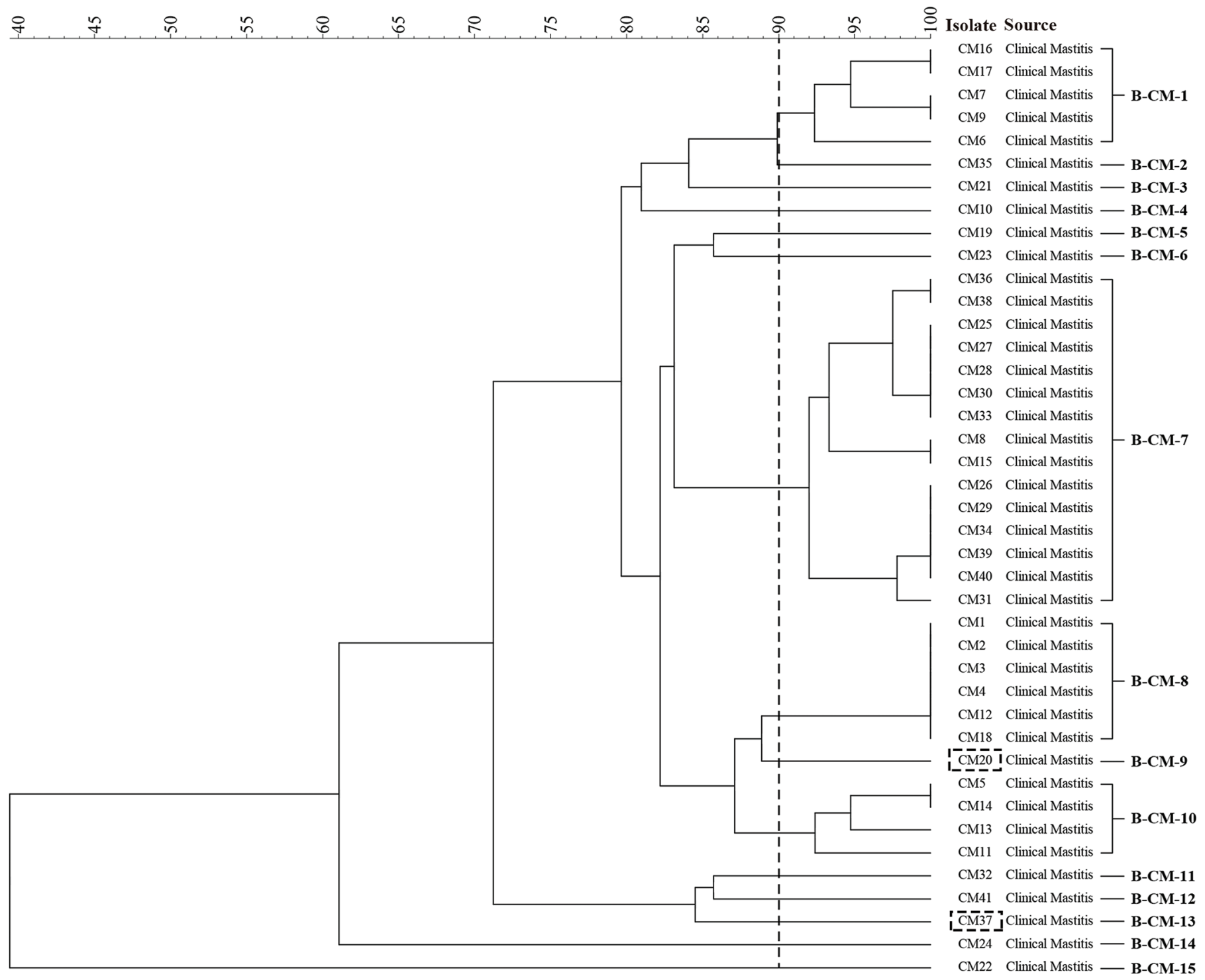

Figure 3. Repetitive DNA sequence PCR (rep-PCR) clustering of 41 Klebsiella pneumoniae isolates from CM on Farm B. Strains with similarity $\geq 90 \%$ were considered as same genotype. Klebsiella pneumoniae isolates $(\mathrm{n}=2)$ marked with boxes were isolated from heifers. 


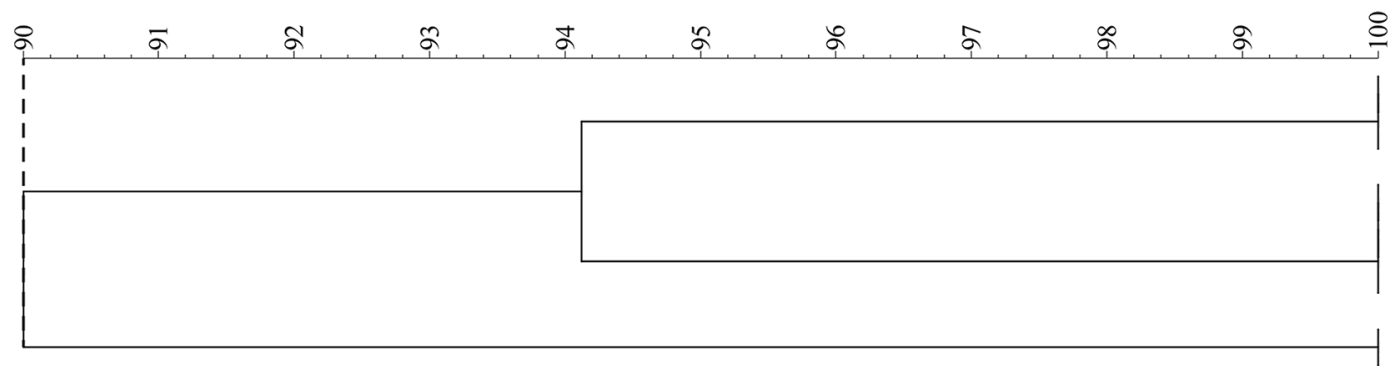

Isolate Source

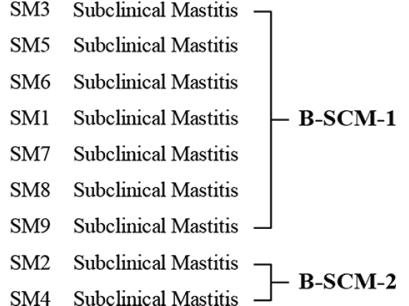

Figure 4. Repetitive DNA sequence PCR (rep-PCR) clustering of 9 Klebsiella pneumoniae isolates from SCM cases on Farm B. Strains with similarity $\geq 90 \%$ were considered the same genotype.

abled us to explore potential transmission and diversity of Klebsiella-associated CM on Chinese dairy farms. Although distinctly different from each other, the 2 farms are representative of the general characteristics of most large Chinese dairy farms (>500 milking cows), based on feeding, milking, and environmental management.

Table 4. Distribution of Klebsiella pneumoniae genotypes on Farm A, according to origin of sample

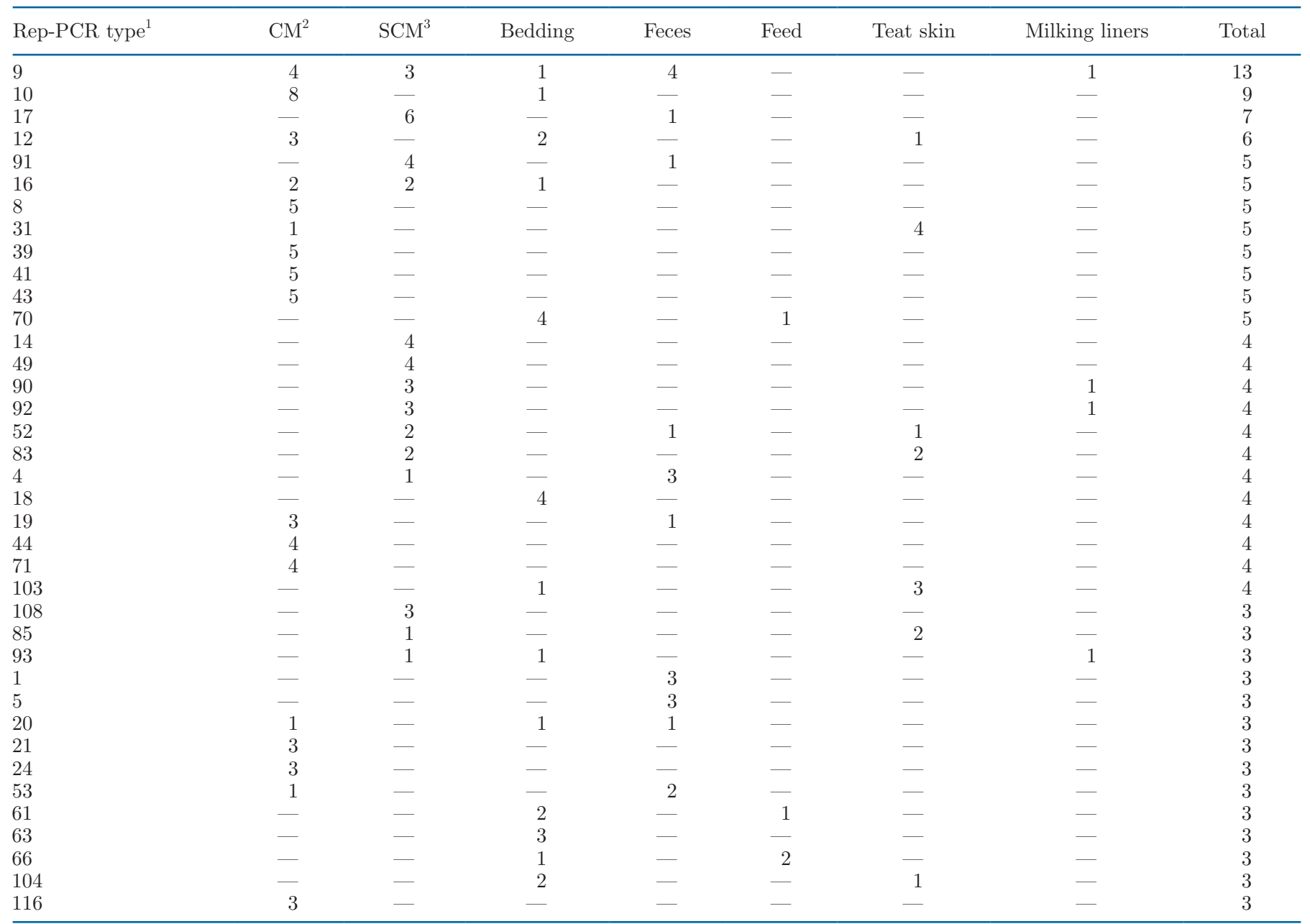

${ }^{1}$ Rep-PCR $=$ repetitive element sequence-based PCR; genotypes with $\geq 3$ isolates included.

${ }^{2} \mathrm{CM}=$ clinical mastitis.

${ }^{3} \mathrm{SCM}=$ subclinical mastitis 
Klebsiella pneumoniae isolation rates were lower in SCM than in CM samples on both farms. On Farm $\mathrm{B}$, the high incidence of $\mathrm{CM}$ caused by $K$. pneumoniae was not attributed to cows with SCM, as those cows had a very low isolation rate of $K$. pneumoniae. These findings were consistent with reports that IMI caused by Gram-negative pathogens leads more often to CM rather than to SCM (Bradley et al., 2007; Botrel et al., 2010; Rowbotham and Ruegg, 2016).

Although we collected a large number of milk samples from CM in a short interval, a high index of diversity was detected within farms, consistent with previous findings (Paulin-Curlee et al., 2008). High genetic diversity within and between farms was expected, as $K$. pneumoniae is an opportunistic, environmental pathogen (Hogan and Smith, 2003; Muñoz et al., 2007a; Paulin-Curlee et al., 2008). Nevertheless, despite increased absolute values, $K$. pneumoniae diversity indexes from environmental or extramammary samples differed between farms. Lower diversity was detected for Farm B in comparison to Farm A, suggesting that either cows on Farm B were exposed to a common extramammary site, or contagious transmission occurred during milking (although K. pneumoniae was not isolated from milking liner samples, the possibility cannot be ruled out due to the limited number of samples). Co-existence of distinct epidemiological transmission pathways of $K$. pneumoniae within a single dairy has been reported, demonstrating the contagious potential of K. pneumoniae (Muñoz et al., 2007a).

Greater diversity was detected in $K$. pneumoniae isolated from SCM on Farm A versus Farm B. Notably, only 2 genotypes were associated with SCM on Farm B, whereas 33 were detected on Farm A. Moreover, diversity of isolates was comparable between CM and SCM samples for Farm A, but not for Farm B. Therefore, we inferred that farm- or cow-level factors differed between farms and influenced the course of IMI caused by $K$. pneumoniae. Notably, only $2 \mathrm{CM}$ isolates were isolated from heifers on Farm B. Regarding cow-level factors, although diversity was not distinguishable between isolates from heifers versus older cows on Farm A, number of genotypes per samples was lower for older cows (33 genotypes and 71 isolates; 0.46 genotypes per isolate) than for heifers (13 genotypes and 17 isolates; 0.76 genotypes per isolate), suggesting that parity or housing (heifers were housed separately from multiparous cows) may account for at least part of the genetic variability of isolates. Alternatively, perhaps there was an increased ability of specific $K$. pneumoniae genotypes to adapt to udders on Farm B (Klaas and Zadoks, 2018). Hence, there is potential to further explore and compare virulence characteristics of $K$. pneumoniae from CM and SCM samples within and between farms, to identify if and which potential virulence factors might be associated with udder adaptability in K. pneumoniae.

Despite increased diversity values, isolates from the same genotypes were detected in different environmental or extramammary sites on both farms. For Farm B, one-third (33\%) of genotypes contained $>1$ isolate. The lower genetic diversity of $K$. pneumoniae isolated from environmental or extramammary sites on Farm B in comparison to Farm A, could have been due to more samples per barn collected on Farm B. Initially, a sample collection protocol was provided to the farm personnel. Unfortunately, farm personnel did not to follow this protocol stringently and samples were therefore not collected as methodically as indicated. Therefore, we must emphasize that comparison of diversity indexes of environmental or extramammary samples from the 2 farms should be interpreted with caution.

In agreement with reports from European and American dairy farms, $K$. pneumoniae was detected in samples from bedding, feces, teat skin, milking lin-

Table 5. Distribution of Klebsiella pneumoniae genotypes on Farm B, according to origin of sample

\begin{tabular}{|c|c|c|c|c|c|c|c|c|}
\hline Rep-PCR type $^{1}$ & $\mathrm{CM}^{2}$ & $\mathrm{SCM}^{3}$ & Bedding & Feces & Feed & Teat skin & Milking liners & Total \\
\hline 23 & - & 2 & 6 & - & - & - & - & 8 \\
\hline 24 & - & 7 & 2 & - & - & - & - & 8 \\
\hline 4 & - & - & - & 1 & - & 6 & - & 7 \\
\hline 20 & 6 & - & - & - & - & - & - & 6 \\
\hline 11 & 5 & - & - & - & - & - & - & 5 \\
\hline 5 & - & - & - & 2 & - & 1 & - & 3 \\
\hline
\end{tabular}

${ }^{1} \mathrm{Rep}-\mathrm{PCR}=$ repetitive element sequence-based PCR; genotypes with $\geq 3$ isolates included.

${ }^{2} \mathrm{CM}=$ clinical mastitis.

${ }^{3} \mathrm{SCM}=$ subclinical mastitis. 
ers and feed (Muñoz et al., 2006; Muñoz and Zadoks, 2007b; Verbist et al., 2011; Zadoks et al., 2011b). In particular, bedding, fecal, and teat skin samples contained $K$. pneumoniae. Nevertheless, isolation rates were distinctly different between farms. On Farm B, all bedding isolates were detected in sawdust bedding, but none in sand bedding. We inferred that sawdust was an important source of Klebsiella spp, as reported by others (Hogan et al., 1989; Zdanowicz et al., 2004). Benefits of using fresh sand bedding to control mastitis have been reported (Rowbotham and Ruegg, 2016), and would be a good choice for dairy farms with a high incidence of Klebsiella mastitis.

Although differences between the 2 farms in number of animals and barns sampled could explain some of our findings, it remains unclear why isolation rates of $K$. pneumoniae from fecal, feed and milking liners differed between these 2 farms. Oral-fecal Klebsiella spp. transmission via contaminated water or feed or via contaminated feed with involvement of the environment has been reported (Zadoks et al., 2011b). Therefore, the lower detection rate in feed and higher detection in feces on Farm A indicated that the intake of $K$. pneumoniae via drinking water should be considered. Perhaps clearance and amplification of K. pneumoniae in rumen of cows differed between dairy farms. Future investigations with more farms with varying farm-level factors should be conducted.

Environmental sampling enables identification of sources of $K$. pneumoniae causing IMI in the environment (Muñoz et al., 2007a). In general, for Farm A, genotypes encountered in feces, bedding, and milking liners were also frequently isolated from SCM and CM. In contrast, for Farm B, teat skin swabs, feed, and sawdust bedding were apparently the most important sources of K. pneumoniae. Interestingly, a predominant genotype (Rep-PCR type 9) was isolated in 4 cases of CM, 3 cases of SCM, and bedding, feces, and milking liners from Farm A. Perhaps this strain was shed in feces, survived in bedding materials, colonized teat ends, and ultimately entered into udders to cause IMI. Detection of this strain in a milking liner sample may have been due to bacteria at the teat end before milking. For Farm B, a predominant strain (rep-PCR type 17) was isolated from 13 cases of CM, 4 feed samples, and 2 teat skin samples. Although this strain could have entered the udder by exposure to feces or bedding, based on failure to detect this strain samples of bedding or feces, we inferred that this means of transmission was unlikely. It is difficult to speculate why the predominant strain causing CM was frequently isolated from feed samples. Regardless, the increased udder adaptability of this strain requires more investigation. As outbreaks of $K$. pneumoniae mastitis were of a very different nature on these 2 farms, we hypothesize that on Farm A: (1) reservoirs for IMI were extramammary or environmental sources, especially in feces and recycled manure solids; and (2) there were common pathways for $K$. pneumoniae to enter and exit the udder, because some IMI isolates shared the same genotypes with extramammary and environmental isolates; whereas on Farm B: (1) strains with increased udder adaptability were present; (2) sawdust was a source of these strains; and (3) there was transmission during milking (although $K$. pneumoniae was not isolated from milking liner samples) or a common extramammary source. Based on our findings, we inferred that a framework for controlling outbreaks of $K$. pneumoniae $\mathrm{CM}$ on large Chinese dairy farms should consider farm-specific management practices, as there was evidence that the 2 outbreaks were distinct in terms of source and spread of IMI.

This study had limitations that need to be acknowledged. Although there were high absolute diversity values, it is unclear whether strain typing a single isolate per sample affected our estimates. Finally, the sampling protocols differed between farms, with a higher proportion of cows (SCM samples) / environmental sites sampled from Farm B than from Farm A; therefore, between-farm differences of diversity indexes and isolation rates of $K$. pneumoniae could have been due to sampling strategies. Yet, we must stress that even for Farm A, a high proportion of cows were sampled for SCM ( $\sim 15 \%$ of lactating cows). In addition, differences in diversity indices observed between farms were also consistent for $\mathrm{CM}$ isolates, where all cows from the 2 farms were eligible for inclusion. Therefore, we believe that any observed between-farm differences reflected true differences at the population level.

\section{CONCLUSIONS}

Two outbreaks of $K$. pneumoniae CM occurred on 2 large Chinese dairy farms, with distinct differences between farms. Despite overall high values, diversity of $K$. pneumoniae was lower for Farm B, suggesting presence of some strains with increased udder adaptability. For Farm A, genotypes from mastitis were mainly encountered in feces, bedding and milking liners, whereas for Farm B, teat skin swabs, sawdust bedding and feed were the most important sources of K. pneumoniae causing IMI. This study highlighted the need to consider within-farm factors when establishing 
a framework to prevent outbreaks of $K$. pneumoniae $\mathrm{CM}$ on large Chinese dairy farms.

\section{ACKNOWLEDGMENTS}

This study was financially supported by Beijing Municipal Natural Science Foundation (No. 6192013), National Key Research and Development Project (2018YFD0501601-01, 2016YFD0501203), the National Natural Science Foundation of China (No. 31660730 and 31550110200), the High-end Foreign Experts Recruitment Program (No. GDT20171100013) and Hebei Key Research and Development Project (19226607D). The authors have not stated any conflicts of interest.

\section{REFERENCES}

Adkins, P. R. F., and J. R. Middleton. 2017. Laboratory Handbook on Bovine Mastitis. National Mastitis Council, Madison, WI

Bagley, S. T., and R. J. Seidler. 1978. Primary Klebsiella identification with MacConkey-inositol-carbenicillin agar. Appl. Environ. Microbiol. 36:536-538. https://doi.org/10.1128/AEM.36.3.536-538 1978 .

Botrel, M. A., M. Haenni, E. Morignat, P. Sulpice, J. Y. Madec, and D. Calavas. 2010. Distribution and antimicrobial resistance of clinical and subclinical mastitis pathogens in dairy cows in RhôneAlpes, France. Foodborne Pathog. Dis. 7:479-487. https://doi.org/ 10.1089 /fpd.2009.0425.

Bradley, A. J., K. A. Leach, J. E. Breen, L. E. Green, and M. J. Green. 2007. Survey of the incidence and aetiology of mastitis on dairy farms in England and Wales. Vet. Rec. 160:253-257. https://doi .org/10.1136/vr.160.8.253.

Cheng, J., W. Qu, H. W. Barkema, D. B. Nobrega, J. Gao, G. Liu, J. De Buck, J. P. Kastelic, H. Sun, and B. Han. 2019. Antimicrobial resistance profiles of 5 common bovine mastitis pathogens in large Chinese dairy herds. J. Dairy Sci. 102:2416-2426. https://doi.org/ $10.3168 /$ jds.2018-15135.

Dairy Association of China. 2017. China Agriculture Press, Beijing, China. pp. 342-350.

Frank, J. A., C. I. Reich, S. Sharma, J. S. Weisbaum, B. A. Wilson, and G. J. Olsen. 2008. Critical evaluation of two primers commonly used for amplification of bacterial $16 \mathrm{~S}$ rRNA genes. Appl. Environ. Microbiol. 74:2461-2470. https://doi.org/10.1128/AEM .02272-07.

Gao, J., H. W. Barkema, L. Zhang, G. Liu, Z. Deng, L. Cai, R. Shan, S. Zhang, J. Zou, J. P. Kastelic, and B. Han. 2017. Incidence of clinical mastitis and distribution of pathogens on large Chinese dairy farms. J. Dairy Sci. 100:4797-4806. https://doi.org/10.3168/ jds.2016-12334.

Gao, J., S. Li, J. Zhang, Y. N. Zhou, S. Y. Xu, H. W. Barkema, D. B. Nobrega, C. Zhu, and B. Han. 2019. Prevalence of potential virulence genes in Klebsiella spp. isolated from cows with clinical mastitis on large Chinese dairy farms. Foodborne Pathog. Dis. 16:856-863. https://doi.org/10.1089/fpd.2019.2657.

Grundmann, H., S. Hori, and G. Tanner. 2001. Determining confidence intervals when measuring genetic diversity and the discriminatory abilities of typing methods for microorganisms. J. Clin. Microbiol. 39:4190-4192. https://doi.org/10.1128/JCM.39.11.4190 $-4192.2001$

Hogan, J., and K. L. Smith. 2003. Coliform mastitis. Vet. Res. 34:507519. https://doi.org/10.1051/vetres:2003022.

Hogan, J. S., K. L. Smith, K. H. Hoblet, D. A. Todhunter, P. S. Schoenberger, W. D. Hueston, D. E. Pritchard, G. L. Bowman,
L. E. Heider, B. L. Brockett, and H. R. Conrad. 1989. Bacterial counts in bedding materials used on nine commercial dairies. J. Dairy Sci. 72:250-258. https://doi.org/10.3168/jds.S0022 -0302(89)79103-7.

Klaas, I. C., and R. N. Zadoks. 2018. An update on environmental mastitis: Challenging perceptions. Transbound. Emerg. Dis. 65(Suppl 1):166-185. https://doi.org/10.1111/tbed.12704.

Muñoz, M. A., C. Ahlström, B. J. Rauch, and R. N. Zadoks. 2006. Fecal shedding of Klebsiella pneumoniae by dairy cows. J. Dairy Sci. 89:3425-3430. https://doi.org/10.3168/jds.S0022-0302(06)72379 $-7$.

Muñoz, M. A., G. J. Bennett, C. Ahlström, H. M. Griffiths, Y. H. Schukken, and R. N. Zadoks. 2008. Cleanliness scores as indicator of Klebsiella exposure in dairy cows. J. Dairy Sci. 91:3908-3916. https://doi.org/10.3168/jds.2008-1090.

Muñoz, M. A., F. L. Welcome, Y. H. Schukken, and R. N. Zadoks. 2007a. Molecular epidemiology of two Klebsiella pneumoniae mastitis outbreaks on a dairy farm in New York State. J. Clin. Microbiol. 45:3964-3971. https://doi.org/10.1128/JCM.00795-07.

Muñoz, M. A., and R. N. Zadoks. 2007b. Short communication: Patterns of fecal shedding of Klebsiella by dairy cows. J. Dairy Sci. 90:1220-1224. https://doi.org/10.3168/jds.S0022-0302(07)71610 $-7$.

Neave, F. K., F. H. Dodd, R. G. Kingwill, and D. R. Westgarth. 1969. Control of mastitis in the dairy herd by hygiene and management. J. Dairy Sci. 52:696-707. https://doi.org/10.3168/jds.S0022 -0302(69)86632-4.

Olde Riekerink, R. G. M., H. W. Barkema, D. F. Kelton, and D. T. Scholl. 2008. Incidence rate of clinical mastitis on Canadian dairy farms. J. Dairy Sci. 91:1366-1377. https://doi.org/10.3168/ jds.2007-0757.

Oliveira, L., C. Hulland, and P. L. Ruegg. 2013. Characterization of clinical mastitis occurring in cows on 50 large dairy herds in Wisconsin. J. Dairy Sci. 96:7538-7549. https://doi.org/10.3168/jds .2012-6078.

Paulin-Curlee, G. G., R. S. Singer, S. Sreevatsan, R. Isaacson, J. Reneau, D. Foster, and R. Bey. 2007. Genetic diversity of mastitis-associated Klebsiella pneumoniae in dairy cows. J. Dairy Sci. 90:3681-3689. https://doi.org/10.3168/jds.2006-776.

Paulin-Curlee, G. G., S. Sreevatsan, R. S. Singer, R. Isaacson, J. Reneau, R. Bey, and D. Foster. 2008. Molecular subtyping of mastitis-associated Klebsiella pneumoniae isolates shows high levels of diversity within and between dairy herds. J. Dairy Sci. 91:554-563. https://doi.org/10.3168/jds.2007-0479.

Pinzón-Sánchez, C., and P. L. Ruegg. 2011. Risk factors associated with short-term post-treatment outcomes of clinical mastitis. J. Dairy Sci. 94:3397-3410. https://doi.org/10.3168/jds.2010-3925.

Qu, Y., H. Zhao, D. B. Nobrega, E. R. Cobo, B. Han, Z. Zhao, S. Li, M. Li, H. W. Barkema, and J. Gao. 2019. Molecular epidemiology and distribution of antimicrobial resistance genes of Staphylococcus species isolated from Chinese dairy cows with clinical mastitis. J. Dairy Sci. 102:1571-1583. https://doi.org/10.3168/jds.2018-15136.

Rowbotham, R. F., and P. L. Ruegg. 2016. Associations of selected bedding types with incidence rates of subclinical and clinical mastitis in primiparous Holstein dairy cows. J. Dairy Sci. 99:47074717. https://doi.org/10.3168/jds.2015-10675.

Ruegg, P. L. 2017. A 100-year review: Mastitis detection, management, and prevention. J. Dairy Sci. 100:10381-10397. https://doi .org/10.3168/jds.2017-13023.

Schalm, O. W., and D. O. Noorlander. 1957. Experiments and observations leading to development of the California mastitis test. J. Am. Vet. Med. Assoc. 130:199-204.

Schukken, Y., M. Chuff, P. Moroni, A. Gurjar, C. Santisteban, F. Welcome, and R. Zadoks. 2012. The "other" gram-negative bacteria in mastitis: Klebsiella, serratia, and more. Vet. Clin. North Am. Food Anim. Pract. 28:239-256. https://doi.org/10.1016/j.cvfa.2012.04 .001 .

Simpson, E. H. 1949. Measurement of diversity. Nature 163:688. https: //doi.org/10.1038/163688a0. 
Verbeke, J., S. Piepers, K. Supre, and S. De Vliegher. 2014. Pathogenspecific incidence rate of clinical mastitis in Flemish dairy herds, severity, and association with herd hygiene. J. Dairy Sci. 97:69266934. https://doi.org/10.3168/jds.2014-8173.

Verbist, B., V. Piessens, A. Van Nuffel, L. De Vuyst, M. Heyndrickx, L. Herman, E. Van Coillie, and S. De Vliegher. 2011. Sources other than unused sawdust can introduce Klebsiella pneumoniae into dairy herds. J. Dairy Sci. 94:2832-2839. https://doi.org/10.3168/ jds.2010-3700.

Zadoks, R. N., H. M. Griffiths, M. A. Muñoz, C. Ahlstrom, G. J. Bennett, E. Thomas, and Y. H. Schukken. 2011b. Sources of Klebsiella and Raoultella species on dairy farms: Be careful where you walk. J. Dairy Sci. 94:1045-1051. https://doi.org/10.3168/jds.2010-3603.

Zadoks, R. N., J. R. Middleton, S. McDougall, J. Katholm, and Y. H. Schukken. 2011a. Molecular epidemiology of mastitis pathogens of dairy cattle and comparative relevance to humans. J. Mammary Gland Biol. Neoplasia. 16:357-372.

Zdanowicz, M., J. A. Shelford, C. B. Tucker, D. M. Weary, and M. A. G. von Keyserlingk. 2004. Bacterial populations on teat ends of dairy cows housed in free stalls and bedded with either sand or sawdust. J. Dairy Sci. 87:1694-1701. https://doi.org/10.3168/jds .S0022-0302(04)73322-6. 